\title{
Selektif Embolizasyonla Tedavi Edilmiş Tonsillektomi Sonrası Ciddi Kanama: Lingual Arter Psödoanevrizması
}

\author{
Özlem Ünsal' ${ }^{1}$ Didem Rıfkı', Ender Uysal'², Berna Uslu Coşkun'
}

\begin{abstract}
ÖZET:
Selektif embolizasyonla tedavi edilmiş tonsillektomi sonrası ciddi kanama: Lingual arter psödoanevrizması

Adenotonsillektomi sonrası 13, 34 ve 40. günlerde masif orofarengeal kanama ile başvuran 5 yaşında kadın hasta vasküler patolojiden şüphelenilerek anjiyografi ile değerlendirildi. Anjiyografide sağ lingual arterde psödoanevrizma tespit edilerek koil ile embolize edildi. Gecikmiş, tonsillektomi sonrası ciddi kanamalarda vasküler patolojiler mutlaka akla getirilmelidir. Anjiyografi bu hastaların hem tanı hem de tedavisinde etkili bir girişimdir.
\end{abstract}

Anahtar kelimeler: Embolizasyon, kanama, psödoanevrizma, tonsillektomi

\section{ABSTRACT:}

Severe post-tonsillectomy haemorrhage treated with selective embolisation: a pseudoaneurysm of the lingual artery

A 5 year old female patient with massive oropharyngeal haemorrhages in $13^{\text {th }}, 34^{\text {th }}$, and $40^{\text {th }}$ days after an adenotonsillectomy is evaluated by angiography because of a suspected vascular abnormality demonstrated a pseudoaneurysm of the right lingual artery. In angiography pseudoaneurysm was found and the affected artery was coil embolisated. Vascular pathologies should be considered in the delayed, severe post-tonsillectomy haemorrhages. Angiography is an effective intervention for both diagnosis and treatment of these patients.

Keywords: Embolization, haemorrhage, pseudoaneurysm, tonsillectomy

Ş.E.E.A.H. Tıp Bülteni 2016;50(1):87-9

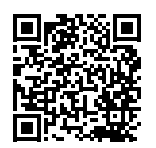

'Şişli Hamidive Etfal Eğitim ve Araştırma Hastanesi, Kulak Burun Boğaz Kliniği, ìstanbul - Türkiye

${ }^{2}$ Şişli Hamidiye Etfal Eğitim ve Araştırma Hastanesi, Radyoloji Kliniği, İstanbul - Türkiye

Yazışma Adresi / Address reprint requests to: Özlem Ünsal,

Şişli Hamidiye Etfal Eğitim ve Araştırma

Hastanesi, Kulak Burun Boğaz Kliniği,

İstanbul - Türkiye

E-posta / E-mail:

ozlemunsal@hotmail.com

Geliş tarihi / Date of receipt:

7 Mayıs 2015 / May 7, 2015

Kabul tarihi / Date of acceptance: 24 Haziran 2015 / June 24, 2015

\section{GíRiş}

Tonsillektomi baş boyun cerrahları tarafından en sık uygulanan cerrahi girişimdir (1). Tonsillektomi çoğunlukla güvenli bir operasyon olmasına karşın büyük arterlerin varyasyonlu seyirleri ve tonsiller bölgeye yakın komşulukları, zengin vasküler ağ ve internal karotis arterin aberan seyri gibi nedenlerle arteryel hasar riskine sahiptir. Postoperatif dönemde primer ve sekonder kanamalar görülebilmektedir $(1,2)$. Ameliyat sonrası ilk 24 saat içinde görülen primer kanamalar \%0.3-2.1 oranında görülürken, sekonder kanamalar \%2-10 oranında karşımıza çıkmaktadır $(1,3,4)$. Arteryel diseksiyonlar ve anevrizmalar tonsillektomi sonrası görülen ciddi kanama nedenleri ara- sında yer almaktadır (5). Sunulan bu olgu, sağ lingual arter psödoanevrizmasına sekonder oluşan ciddi orofaringeal kanama ile başvurmuş ve selektif arteryel embolizasyonla tedavi edilmiştir.

\section{OLGU}

5 yaşında kadın hasta hastanemiz dışı bir merkezde adenotonsillektomi ameliyatı olduktan 13 gün sonra ciddi orofaringeal kanama yakınması ile hastanemizin çocuk acil polikliniğine başvurmuş. Başvuru anında yapılan muayenesinde aktif bir kanama odağı saptanmayan hasta tarafımıza yönlendirildikten sonra tonsillektomi sonrası kanama ön tanısı ile kulak burun boğaz hastalıkları baş ve boyun cerrahisi klini- 
ğine yatırıldı. 3 günlük yatış ve takip süresince herhangi bir kanama izlenmemesi üzerine hasta, gerekli önerilerde bulunularak taburcu edildi. Hasta, ameliyattan sonraki 34. günde ciddi orofaringeal kanama şikayeti ile yeniden hastanemiz acil polikliniğine başvurdu. Çocuk hastalıkları, çocuk cerrahisi, kulak burun boğaz hastalıkları (KBB) uzmanları tarafından değerlendirilen ve kanamadan önce herhangi bir

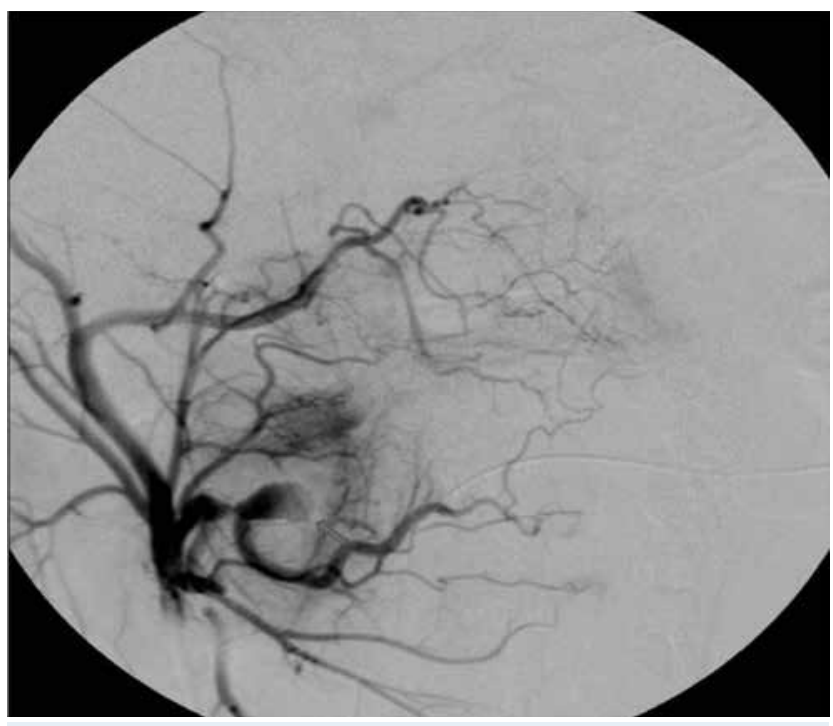

Şekil-1: Anjigrafide eksternal kartik arterin lateral izdüşümünde, lingual arterin proksimal sehmentimnde bir pseudoanevrizma görülmektedir.

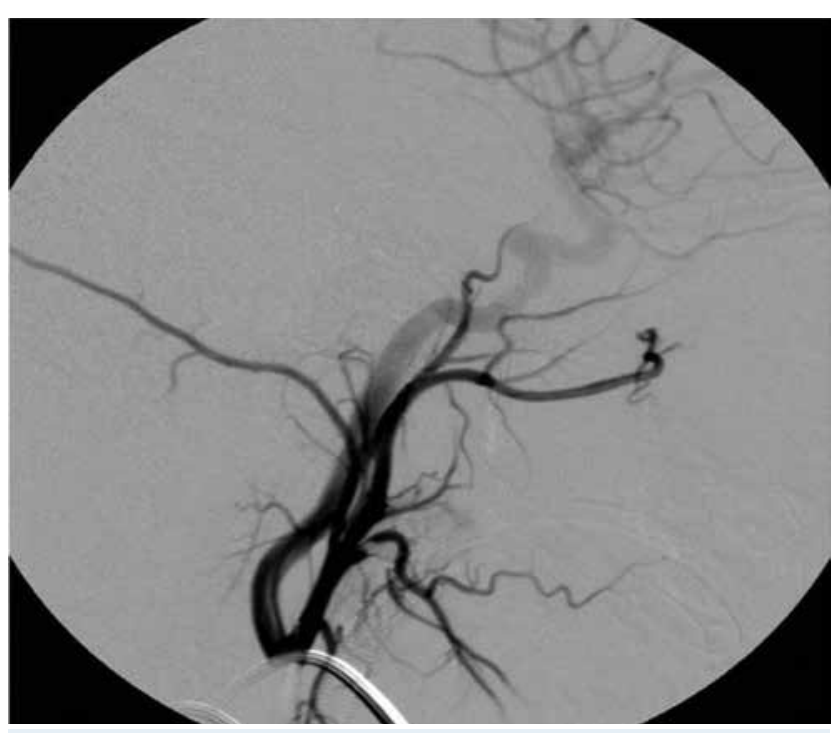

Şekil-2: Endovasküler coil embolizasyondan sonra pseudoanevrizma dolmuyor. provokatif olayın gerçekleşmediği belirlenen hastanın ciddi, aktif orofaringeal kanaması mevcuttu. Değerlendirilebildiği kadarıla tonsiller fossa tamamen iyileşmiş görünümdeydi ve kanamanın daha inferior lokalizasyonlu olduğu düşünüldü. Tonsillektomi sonrası gecikmiş kanama ve özofagus varis kanaması ayırıcı tanıya alınarak hastanın genel anestezi altında muayenesine karar verildi. Hasta ameliyathaneye alındığında kanama kendiliğinden durmuştu. Genel anestezi altında yapılan muayene esnasında sağ tonsiller bölge ile dil kökü arasında pulsatil olmayan, yüzeyden kabarık morumsu kitlesel bir lezyon görüldü. Orofaringeal bölgenin aspirasyonu sırasında bu lezyondan yoğun bir kanama başladı ve bipolar koterizasyon ile kontrol altına alındı. Hastanın hemodinamisinin stabilizasyonu için kan transfüzyonu yapıldı. Vasküler patolojiden şiddetle şüphelenilmesi üzerine anjiyografi yapılmasına karar verildi. Hastanın ailesinden bilgilendirilmiş onam formu alındı. Anjiografiden 1 gün önce (postoperatif 40. gün) kanama tekrarladı ve spontan olarak durdu.

Genel anestezi altında sağ femoral arterden yapılan anjiografide sağ lingual arter proksimalinde, 10x6 $\mathrm{mm}$ boyutlarında psödoanevrizma tespit edildi ve coil ile selektif olarak oblitere edildi (Şekil-1, 2). Herhangi bir komplikasyonla karşılaşılmadı. Girişimden 3 gün sonra hasta sorunsuz olarak taburcu edildi.

\section{TARTIŞMA}

Tonsillektomi sonrası kanamalar KBB ve başboyun cerrahları için halen önemli bir problemdir ve tonsillektomi sonrası morbiditenin başlıca sebebidir (6). Tonsillektomi sırasında, keskin ve künt diseksiyon ya da hemostaz için atılan sütürler arteryel intima ve adventisya tabakalarında ayrılmaya, progresif olarak genişleyen periarteryel hematoma neden olur. Likefaksiyona bağlı olarak hematomun ortasında potansiyel bir boşluk meydana gelir. Bu boşluk hasara uğramış olan arter ile bağlantı oluşturarak psödoanevrizma olarak tanımlanan damarsal bir genişleme ortaya çıkar (2). Boyunda psödoanevrizma formasyonu, radyoterapi, peritonsiller apse ve lokal enfeksiyonlara bağlı olarak da görülebilmektedir. Ancak bunlar tonsillektomi sonrası görülenlerden farklı olarak kendiliğinden patlamazlar (2). Psödoanevrizmalar ya intrao- 
peratif olarak ya da ameliyattan sonra geç dönemde oluşurlar. Literatürde, 58. günde psödoanevrizma kanaması geçiren bir olgu bildirilmiştir (7). Van Cruijden ve arkadaşları (5) 10 yaşından önce psödoanevrizma kanaması görülmediğini belirtmiş olsalar da literatürde 2 (8), 3 (9), 5 (7,10), 7 (11-13), $8(14,15)$ ve 9 (16) yaşlarındaki olgular tartışılmıştır. İlk semptom, genellikle tekrarlayıcı, masif, fışkırır tarzda ve kendiliğinden durma eğilimi gösteren ciddi orofaringeal kanamadır. Boyun ya da farenkste pulsatil kitle görülmesi nadirdir (5). Arteriyografi, ultrasonografi ve kontrastlı tomografi tanısal görüntüleme yöntemleridir. Bunlar içinde arteriografi, hem tanı hem de tedavi olanağı sağlaması açısından birinci tercihtir. Tonsillektomi sonrası kanamaya bağlı morbiditenin azalmasında embolizasyon oldukça önemlidir. Embolizasyon ligasyondan daha selektif bir yöntem olmasından dolayı, vasküler patoloji düşünülen olgularda şiddetle önerilmektedir $(5,6)$. İlk arteriografide normal bulgular saptansa dahi kanamanın tekrarladığı olgularda arteriografi tekrarlanmalıdır. Maurer ve arkadaşları (11) postoperatif 10 . günde normal arteriyografik bulguları olan ancak ilk girişimden 8 gün sonra tekrar kanama geçiren hastalarına ikinci bir arteriografi yap-

\section{KAYNAKLAR}

1. Kvaerner KJ. Benchmarking surgery: secondary post-tonsillectomy hemorrhage 1999-2005. Acta Otolaryngol 2009; 129: 195-8. [CrossRef]

2. Windfuhr JP, Sesterhenn AM, Schloendorff G, Kremer B. Posttonsillectomy pseudoaneurysm: an underestimated entity? J Laryngol Otol 2010; 124: 59-66. [CrossRef]

3. Murty GE, Watson MG. Diathermy haemostasis at tonsillectomy: current practice-a survey of UK otolaryngologists. J laryngol Otol 1990; 104: 549-52. [CrossRef]

4. Carmody D, Vamadevan T, Cooper SM. Post tonsillectomy haemorrhage. J Laryngol Otol 1982; 96: 635-8. [CrossRef]

5. Van Cruijsen N, Geavendeel J, Dikkers FG. Severe delayed posttonsillectomy haemorrhage due to a pseudoaneurysm of the lingual artery. Eur Arch Otorhinolaryngol 2008; 265: 115-7. [CrossRef]

6. Levy El, Horowitz MB, Cahill AM. Lingual artery embolization for severe and uncontrollable postoperative tonsillar bleeding. Ear Nose Throat J 2001; 80: 208-11.

7. Winfuhr JP, Schlöndorff $G$, Sesterhenn AM, Kremer B. From the expert's office: localized neural lesions following tonsillectomy. Eur Arch Otorhinolaryngol 2009; 266: 1621-40. [CrossRef]

8. Karas DE, Sawin RS, Sie KC. Pseudoaneurysm of the external carotid artery after tonsillectomy. A rare complication. Arch Otolaryngol Head Neck Surg 1997; 123: 345-7. [CrossRef] mışlar ve bir psödoanevrizma ile karşılaşmışlardır.

Bizim olgumuzda, arteriografi ikinci ciddi kanamadan sonra planlanmış ve sağ lingual arter proksimalinde psödoanevrima saptanarak değişik boyutta coil ler ile bağlanmıştır/daraltılmıştır.

\section{SONUÇ}

Tekrarlayıcı, masif, hayatı tehdit eden ve kendiliğinden durma eğilimi tonsillektomi sonrası kanamalarda psödoanevrizmalar mutlaka akla getirilmelidir. Psödoanevrizmal kanamalar hemorajik şok ve ölümle sonuçlanabilir. Erken tanı ve tedavi bu nedenle hayat kurtarıcıdır. Bir vasküler patolojiden şüphelenmek doğru tanıya ulaşmada birinci adımdır. Arteriografi hem tanısal hem de terapötik bir yöntemdir. Embolizasyon, ligasyona kıyasla daha selektif ve tonsillektomi sonrası kanamalara bağlı morbiditenin azaltılmasında oldukça etkilidir. Sunulan bu olgu, tonsillektomi sonrası geç dönemde karşılaşılan abondan, tekrarlayıcı ve kendiliğinden durma eğilimi gösteren kanamalarda vasküler patolojileri ön planda düşünmek gerektiğini göstermesi açısından önemlidir.

9. Mitchell RB, Pereira KD, Lazar RH, Long TE, Fournier NF. Pseudoaneurysm of the right lingual artery: an unusual cause of severe hemorrhage during tonsillectomy. Ear Nose Throat J 1997; 76: 575-6.

10. Weber R, Keerl R, Hendus J, Kahle G. An emergency situation: traumatic aneurysm in head-neck-region. Laryngorhinootologie 1993; 72: 86-90. [CrossRef]

11. Maurer J, Beck C, Mann W. Aneurysm of the lingual artery as a cause of recurrent late hemorrhage following tonsillectomy. Laryngorhinootologie 1989; 68: 301-3. [CrossRef]

12. Menauer F, Suckfull M, Stabler A, Grever G. Pseudoaneurysm of the lingual artery after tonsillectomy. A rare complication. Laryngorhinootologie 1999; 78: 405-7. [CrossRef]

13. Hoff M, Graumuller S, Pau HW. Arterial aneurysms as cause of gushing post-tonsillectomy hemorrhage. Laryngorhinootologie 2005; 84: 680-2. [CrossRef]

14. DeFatta RJ, Verret DJ, Bauer P. Extracanial internal carotid artery pseudoaneurysm. Int J Pediatr Otorhinolaryngol 2005; 69: 11359. [CrossRef]

15. Simoni P, Bello JA, Kent B. Pseudoaneurysm of the lingual artery secondary to tonsillectomy treated with selective embolization. Int J Pediatr Otorhinolaryngol 2001; 59: 125-8. [CrossRef]

16. Heyn G, Metz L, Olthoff G. Aneurysm of the extracranial internal carotid artery (in German). Zentralbl Chir 1986; 111: 1312-20. 